\title{
What Makes Digital Content Influential? A Comparison of Celebrities and Influencers: An Abstract
}

\author{
Kirsten Cowan and Laura Hunt
}

\begin{abstract}
The use of social media in promotional campaigns has gained momentum, especially concerning the creation of marketing campaigns involving social media influencers. Influencers have traditionally created their own user-generated content (UGC) like blogs or vlogs. Moreover, marketers identify UGC as effective for brand promotion because consumers perceive it as more credible than marketergenerated content (MGC) and have paid celebrities and social media influencers to create UGC. The lack of research aimed at investigating how influencers (vs. celebrities) persuade consumers with UGC versus MGC motivates this research.

Using source effects theory and processing fluency to inform the research, one 2 (content: UGC vs. MGC) × 2 (endorser: celebrity vs. social media influencer) between subjects design was conducted using a snowball sample on social media targeting European women $\left(n=138 ; M_{\text {age }}=25\right)$ participants on social media. The results revealed a significant two-way interaction on attitudes toward the brand and purchase intentions. Post hoc analysis indicated that UGC leads to higher attitudes toward the brand and intentions to purchase the product featured when using social media influencers. Additionally, when using MGC, a celebrity endorser generates higher attitudes toward the brand and intentions to purchase the product.

These findings provide several theoretical and practical implications. First, the results suggest that the effectiveness of marketing communication resides in the interaction of the endorser and the content type, consistent with processing fluency. Second, the results indicate that UGC is most effective when the endorser is an influencer versus a celebrity. Likewise, an influencer is most persuasive with UGC rather than appearing in content the brand has created to feature the endorser. Third, the research illustrates that certain source characteristics (e.g., power vs. trust) may explain why UGC (vs. MGC) is more successful when using influencers (vs. celebrities).
\end{abstract}

References Available Upon Request

K. Cowan $(\bowtie) \cdot$ L. Hunt

NEOMA Business School, Mont-Saint-Aignan, France

e-mail: kirsten.cowan@neoma-bs.fr; laura.hunt17@neoma-bs.com

(C) Academy of Marketing Science 2019 